\title{
Mechanical mitral valve thrombosis in rheumatic valve disease
}

\author{
Neda Noroozian, Ahmed Bashir, William Bradlow, Sohail Q Khan
}

Department of Cardiology, University Hospital Birmingham, Birmingham, West Midlands, UK

\section{Correspondence to}

Dr Sohail Q Khan, sohail.khan@uhb.nhs.uk

Accepted 24 January 2014

\section{DESCRIPTION}

A lady in her late 30 s was admitted with a 2-week history of shortness of breath and productive cough. She had been treated for presumed lower respiratory tract infection but had not clinically improved. Her medical history includes rheumatic fever in childhood and she had undergone bioprosthetic mitral replacement (Carpentier-Edwards) 15 years ago. She had redo-surgery with mitral $(25 \mathrm{~mm}$ carbomedics) and aortic (21 mm carbomedics) replacement and tricuspid repair 6 years ago. She was on long-term treatment with phenindione (allergy to warfarin) but due to supply problems had been switched to sinthrone recently. Her anticoagulation record confirmed subtherapeutic International Normalised Ratios for the past 2-3 months.

The patient underwent a transthoracic echocardiogram which revealed an increased gradient across the mitral valve suggestive of valve obstruction (figure $1 \mathrm{~A})$.
Transoesophageal echocardiogram (TOE) showed that one of the mitral valve leaflets was immobile and stuck between an open and closed position (figure 1B,C; videos 1 and 2) with a thrombus seen on the annulus. The left atrium was severely dilated with thrombus in the left atrial appendage (figure 2A,B).

Urgent cardiothoracic surgery was considered to be high risk due to her unstable state and a background of two previous thoracotomies and she received thrombolysis with streptokinase followed by a heparin infusion. She experienced transient inferior ST-segment elevation on her ECG with chest pain which was managed conservatively. Her clinical condition gradually improved and there were no neurological sequelae. Repeat TOE showed resolution of thrombus (figure 3A and video 3) and the normalisation of gradient across the mitral valve (figure 3B).

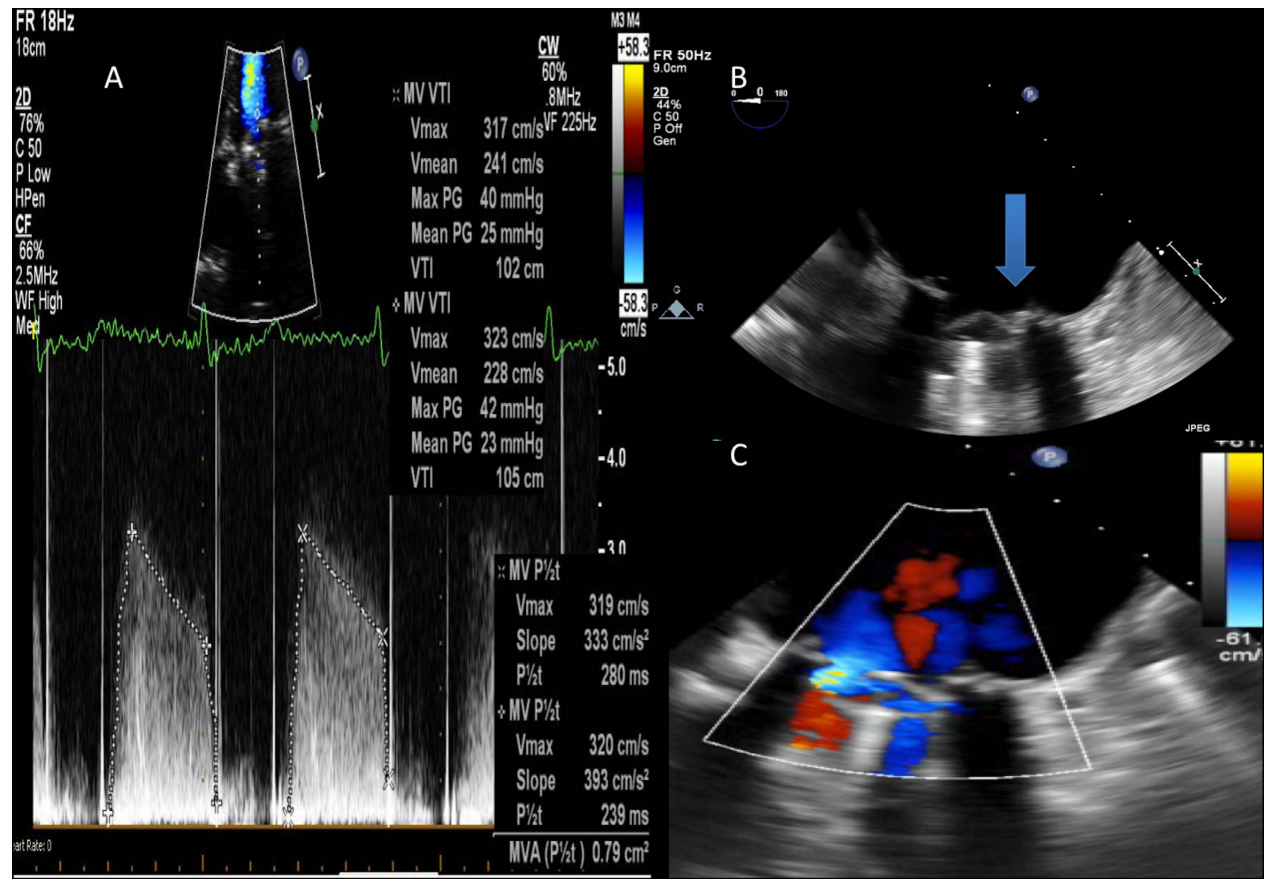

Figure 1 (A) Transthoracic echo showing increased gradient across the mitral valve suggestive of obstruction. (B and C) (videos 1 and 2) two-dimensional transoesophageal echocardiography and colour Doppler showing stuck mitral valve leaflet between an open and closed position with no forward flow with a possible thrombus seen on the annulus (bold arrow pointing towards the stuck leaflet). 

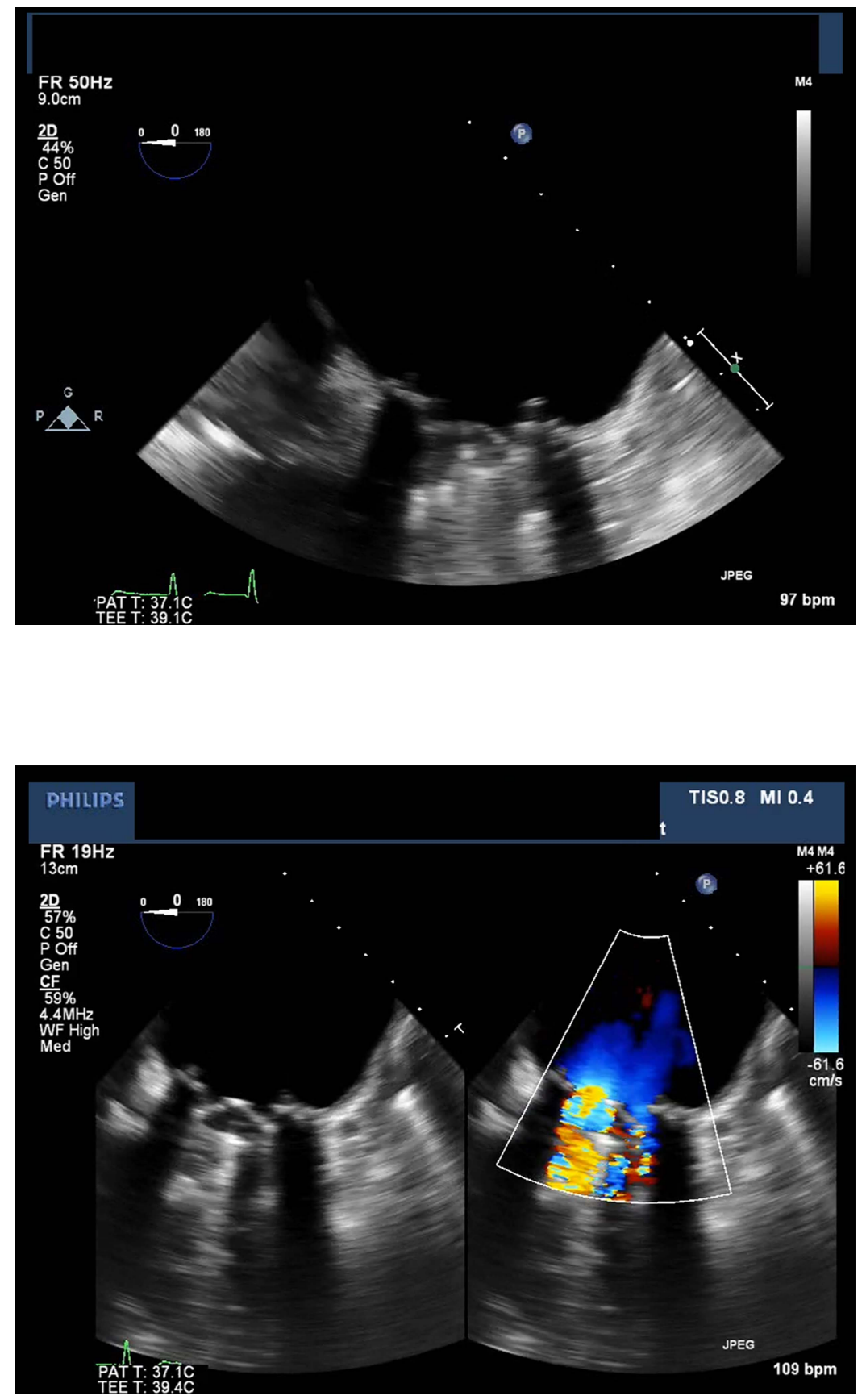

Videos 1 and 2 Two-dimensional transoesophageal echocardiography and colour Doppler showing stuck mitral valve leaflet between an open and closed position with no forward flow with a possible thrombus seen on the annulus (bold arrow pointing towards the stuck leaflet). 


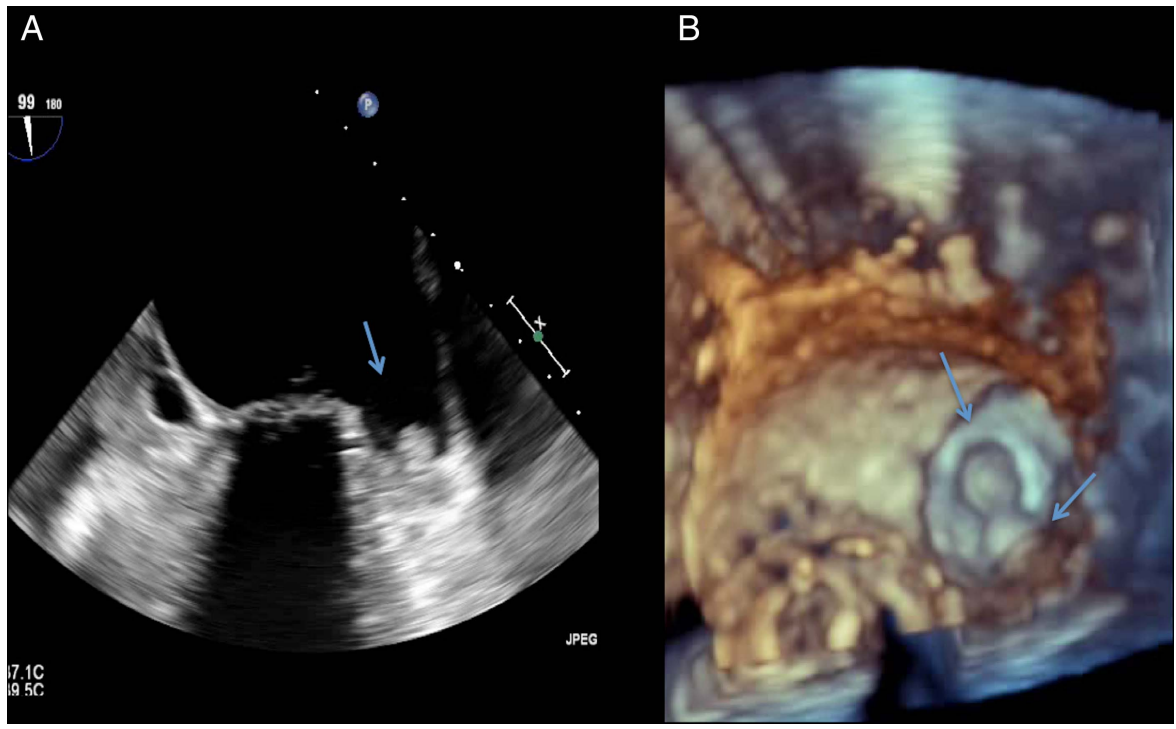

Figure 2 (A) Two-dimensional transoesophageal echocardiography showing thrombus in left atrial appendage (arrow pointing towards thrombus in left atrial appendage). (B) Three-dimensional transoesophageal echocardiography showing thrombi in left atrial appendage (arrows pointing towards thrombi in left atrial appendage).

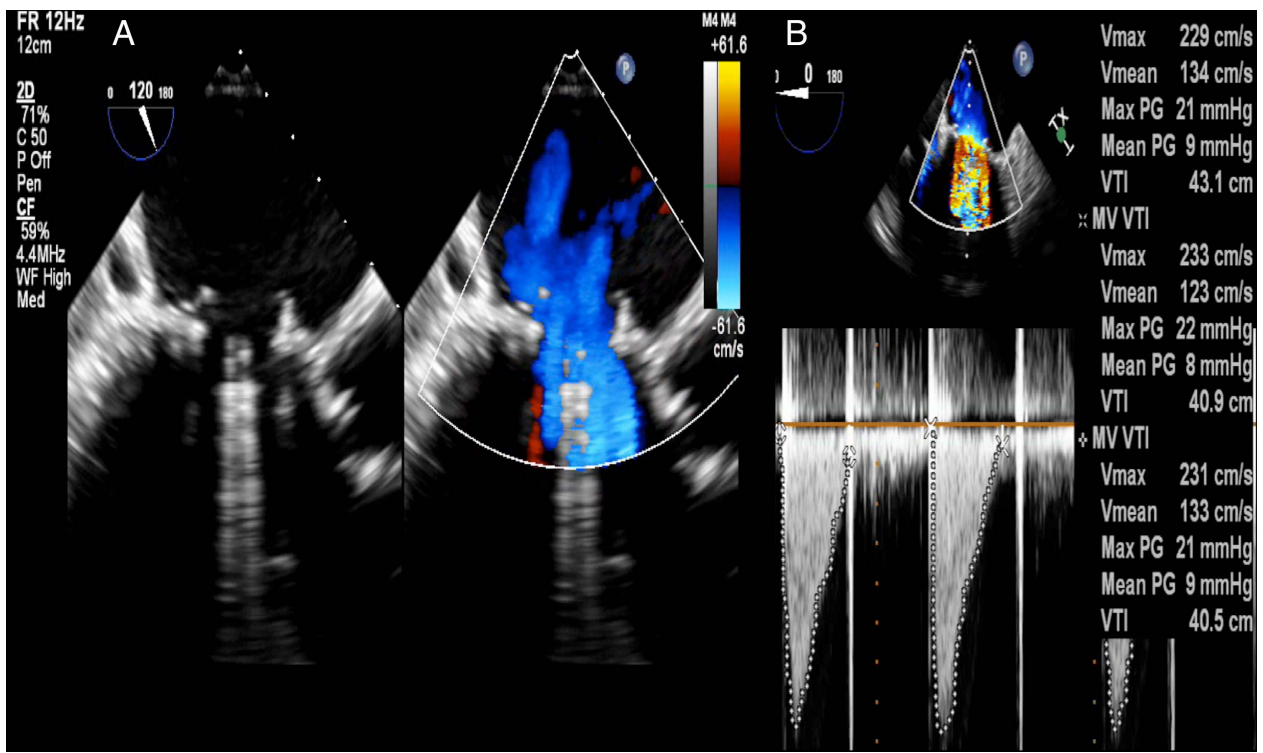

Figure 3 (A) (video 3) Repeat two-dimensional transoesophageal echocardiography and colour Doppler showing resolution of thrombus. (B) Repeat transoesophageal echocardiography showing normalisation of gradient across the mitral valve. 


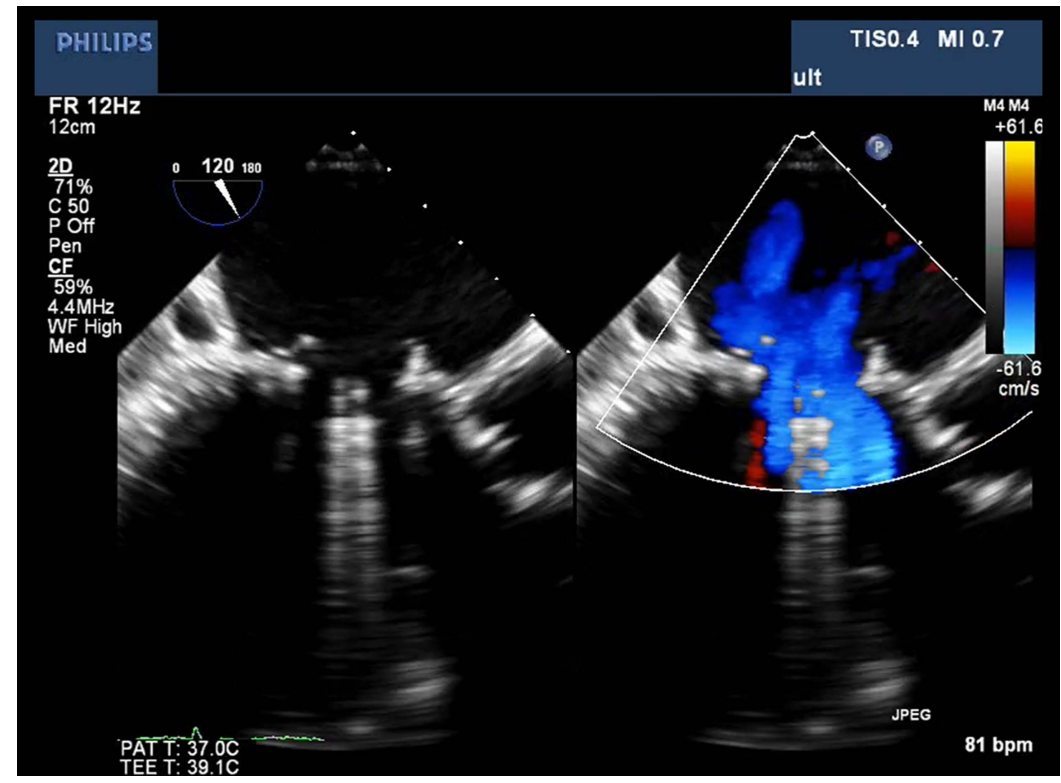

Video 3 Repeat two-dimensional transoesophageal echocardiography and colour Doppler showing resolution of thrombus.

\section{Learning points}

- Prosthetic valve thrombosis is a recognised risk in patients with metallic valves and is more common in patients with subtherapeutic international normalised ratios. ${ }^{1}$

- Any change in the anticoagulation regime of a patient should lead to more frequent monitoring of the INR.

- In treatment of prosthetic valve thrombosis, surgery is the preferred treatment option. Thrombolysis should be considered when surgery is high risk or not immediately available. $^{2}$
Contributors NN participated in drafting the article. AB participated in drafting the article, acquisition of the data and interpretation of the data. WB participated in acquisition of the data and interpretation of the data. SQK was involved in the conception and design, revision of the article and final approval.

Competing interests None.

Patient consent Obtained.

Provenance and peer review Not commissioned; externally peer reviewed.

\section{REFERENCES}

1 Vongpatanasin W, Hillis LD, Lange RA. Prosthetic, heart valves. N Engl J Med 1996;8:407-16.

2 Vahanian A, Alfieri O, Andreotti F. Guidelines on the management of valvular heart disease (version 2012). Eur Heart J 2012;33:2451-96.

Copyright 2014 BMJ Publishing Group. All rights reserved. For permission to reuse any of this content visit http://group.bmj.com/group/rights-licensing/permissions.

BMJ Case Report Fellows may re-use this article for personal use and teaching without any further permission.

Become a Fellow of BMJ Case Reports today and you can:

- Submit as many cases as you like

- Enjoy fast sympathetic peer review and rapid publication of accepted articles

- Access all the published articles

- Re-use any of the published material for personal use and teaching without further permission

For information on Institutional Fellowships contact consortiasales@bmjgroup.com

Visit casereports.bmj.com for more articles like this and to become a Fellow 